Article

\title{
Menurunkan Indeks Glikemik Beras Putih Melalui Proses Pratanak
}

\author{
Margono $^{1, a}$, Fawnia Hanifah ${ }^{1}$, Ameilia Ayu Safitri ${ }^{1}$, Bregas Siswahjono TS ${ }^{1}$, Paryanto, Joko \\ Waluyo $^{1}$, Ari Diana Susanti ${ }^{1}$ and Prabang Setyono ${ }^{2}$ \\ 1 Program Studi Sarjana Teknik Kimia, Fakultas Teknik, Universitas Sebelas Maret \\ 2 Program Studi Ilmu Lingkungan, Fakultas Matematika dan Pengetahuan Alam, Universitas Sebelas Maret \\ aE-mail: margono@ft.uns.ac.id (Corresponding author)
}

\begin{abstract}
Rice is a carbohydrate source and staple food for around the world of people, especially in Asia. Carbohydrate consumption, especially rice, can have effects on diabetes disease type 2. It is caused by the glycemic index of white rice, which is higher than 56 . This research was conducted to study the effects of parboiled ciherang rice and extract of keji beling leaf. The rice was submerged for 6 hours, so the moisture increased to $30 \%$. It was cooked in an autoclave at $116^{\circ} \mathrm{C}$ for 15 minutes. The cooked rice then it was dried at $50^{\circ} \mathrm{C}$ for 24 hours. This method didn't have effects on reducing glycemic index, but it increased the glycemic index higher than 54, e.g. 56 by tester 1 and 80 by tester 2 .
\end{abstract}

Keywords: rice, glycemic index, parboiled, ciherang.

EQUILIBRIUM Volume 4 No.2 December 2020

Online at http:// equilibrium.ft.uns.ac.id 


\section{Pendahuluan}

Beras merupakan makanan pokok sebagian besar penduduk dunia, khususnya asia. Lebih dari 50\% penduduk dunia mengkonsumsi beras sebagai makanan pokoknya [5]. Sembilan puluh persen lebih produksi beras dikonsumsi oleh penduduk di asia [4]. Pola hidup dalam mengonsumsi karbohidrat, khususnya nasi, dapat berakibat pada kegemukan atau komplikasi penyakit diabetes tipe 2. Menurut International Diabetes Federation (2019), pada tahun 2019, 463 juta orang di dunia menderita diabetes dan berakibat pada 4,2 juta kematian serta biaya pengobatan sebesar US \$760,3 miliar [3].

Dalam perkembangannya, terkait dengan pengaruh makanan terhadap kadar gula darah telah dimunculkan sebuah parameter yang dapat dijadikan rujukan dalam memilih maupun menentukan jumlah konsumsi suatu jenis makanan, yaitu indeks glikemik (IG). Pengetahuan terkait nilai IG suatu makanan menjadi hal yang penting bagi seorang penderita diabetes agar dapat melakukan konsumsi makanan secara sehat. Berdasarkan parameter IG ini makanan dibedakan menjadi 3 kelompok, yaitu IG rendah, sedang, dan tinggi. IG dikatakan rendah jika kurang dari 55, sedang jika 56 - 70, dan tinggi jika bernilai lebih dari 70 . Indeks glikemik (IG) adalah suatu ukuran bagi sumber makanan dilihat dari efeknya terhadap kadar gula (glukosa) darah. Makanan dengan IG tinggi dapat meningkatkan kadar gula darah dengan cepat, sedangkan yang ber-IG rendah bedampak pada kenaikan gula darah secara lambat ketika dikonsumsi [7]. Berbagai nilai IG beras dan kriterianya ditunjukkan pada Tabel 1 [8].

Tabel 1. Nilai indeks glikemik beras beberapa varietas padi

\begin{tabular}{clccc}
\hline No. & \multicolumn{1}{c}{ Varietas Padi } & $\begin{array}{c}\text { Kadar } \\
\text { Amilosa }(\%)\end{array}$ & $\begin{array}{c}\text { Indeks } \\
\text { Glikemik }\end{array}$ & Keterangan \\
\hline 1. & Cisokan & 26,7 & 34 & rendah \\
2. Margasari & 25,0 & 39 & rendah \\
3. IR36 & 27,3 & 45 & rendah \\
4. Logawa & 25,5 & 49 & rendah \\
5. Martapura & 26,4 & 50 & rendah \\
6. Air Tenggalung & 28,6 & 50 & rendah \\
7. & Batang Lembang & 25,6 & 54 & rendah \\
8. & Ciherang & 22,9 & 54 & rendah \\
9. Aek Sibundong (beras merah) & 22,0 & 56 & sedang \\
10. IR42 & 26,3 & 58 & sedang \\
11. Beras Taj Mahal & 28,0 & 60 & sedang \\
12. Cigeulis & 21,1 & 64 & sedang \\
13. IR64 & 24,0 & 70 & sedang \\
14. Batang Piaman & 29,4 & 71 & tinggi \\
15. Setail (ketan hitam) & 7,7 & 74 & tinggi \\
16. Ketonggo (ketan putih) & 7,5 & 79 & tinggi \\
17. Ciliwung & 26,2 & 86 & tinggi \\
18. Mekongga & 23,1 & 88 & tinggi \\
19. Sintanur & 15,4 & 91 & tinggi \\
20. Celebes & 19,8 & 95 & tinggi \\
21. Gilirang & 16,6 & 97 & tinggi \\
22. & Bengawan Solo & 17,2 & 106 & tinggi \\
23. Ciasem (ketan putih) & 7,3 & 130 & tinggi \\
\hline
\end{tabular}

Ada 3 upaya yang dapat menjadi pilihan ketika ingin mengkonsumsi beras yang ber-IG rendah, yaitu memilih beras yang secara alami dikenal sebagai beras IG rendah (lihat Tabel 1), membuat beras analog (beras tiruan) dari bahan-bahan yang berIG rendah, atau mengolah beras yang ber IG sedang - tinggi menjadi beras berIG rendah. Budijanto dkk. [1] menguji beras analog yang dibuat dari jagung, sorghum, serta sagu aren dan hasilnya menunjukkan nilai IG sebesar 47,09. Dari ketiga pilihan tersebut, mengingat umumnya orang terbiasa mengonsumsi beras putih yang dirasakannya enak walaupun IG nya tinggi maka orang sulit untuk berpindah ke jenis beras IG rendah (misalnya beras merah atau hitam) karena rasanya tidak sesuai dengan selera kebiasaan. Berangkat dari alasan ini maka pengolahan beras putih ber IG sedang - tinggi menjadi IG rendah merupakan alternatif dalam penyediaan beras bagi penderita diabetes. 
Septianingrum dkk. [6] menjelaskan bahwa nilai IG beras dipengaruhi oleh beberapa faktor, yaitu varietas beras, perbandingan amilosa/amilopektin dalam beras, dan proses pengolahan beras. Beras dengan kandungan amilosa tinggi cenderung memiliki IG rendah. Proses pratanak atau penambahan senyawa polifenol dapat menurunkan IG beras. Hal ini ditunjukkan pada saat pengukuran nilai IG beras melalui pengaruh konsumsi nasi (beras) terhadap luas kurva respon glukosa darah. Hamad dkk. [2] mengungkapkan bahwa mengkonsumsi beras pratanak dapat menurunkan luas di bawah kurva respon glukosa darah hingga $38 \%$ untuk penderita diabetes dan 35\% untuk orang sehat. Penurunan luas area di bawah kurva tersebut sebanding dengan penurunan nilai IG.

Penelitian ini dimaksudkan untuk melakukan studi pengaruh penambahan ekstrak daun keji beling pada proses pratanak beras terhadap pola respons glukosa darah. Lebih lanjut pola respon tersebut digunakan untuk menghitung nilai indeks glikemik beras terkait. Varietas beras yang dipelajari adalah beras ciherang.

\section{Metode}

\subsection{Bahan}

Beras. Beras ciherang diperoleh dari gabah terpilih berkualitas benih dari toko pertanian di Boyolali. Ekstrak daun keji beling. Ekstrak dibuat dengan cara memanaskan bubuk daun keji beling pada $90{ }^{\circ} \mathrm{C}$ di dalam aquades dengan perbandingan $1 \mathrm{~g}$ daun : $100 \mathrm{~mL}$ aquades.

\subsection{Alat}

Alat utama penelitian terdiri atas autoklaf, magnetic heat stirrer, dan oven pengering. Alat pendukung terdiri atas alat-alat gelas dan alat analisis berupa multi function monitoring system merk easy touch GCU.

\subsection{Cara kerja}

Beras yang sudah ditimbang $100 \mathrm{~g}$ dicuci bersih dan ditiriskan. Beras bersih direndam dalam air (ekstrak daun keji beling) dengan perbandingan 1:1 selama 6 jam. Beras hasil rendaman dipanaskan dengan autoklaf pada suhu $116^{\circ} \mathrm{C}$ selama 15 menit. Berikutnya beras dipanaskan dalam oven pada suhu $50^{\circ} \mathrm{C}$ selama 24 jam hingga kering.

\subsection{Analisis glukosa darah}

Beras hasil pratanak ditimbang 69,7 g dan ditanak menggunakan alat penanak nasi listrik (magicjar). Nasi yang telah masak dimakan oleh penguji yang sebelumnya telah berpuasa (menahan dari makan dan minum) sekitar 8 - 10 jam. Sampling darah diambil pada saat 0 jam (sebelum makan), 30 menit, 60 meit, 90 menit, dan 120 menit. Hasil pengukuran glukosa darah digambarkan dalam bentuk grafik. Grafik yang sama dibuat dari hasil respon terhadap makan $50 \mathrm{~g}$ glukosa. Indeks glikemik dihitung berdasarkan perbandingan luas daerah respon sampel terhadap luas daerah respon glukosa menggunakan persamaan (1).

$$
I G=\frac{\text { luas daerah respon sampel }}{\text { luas daerah respon glukosa }} \times 100
$$

\section{Hasil dan Pembahasan}

Proses pratanak didasarkan pada pola kadar air dalam beras hasil perendaman sebagai fungsi waktu. Kenaikan kadar air akibat perendaman beras poles cepat mencapai tingkat kejenuhan, yaitu dalam waktu 0,5 jam perendaman. Berbeda dengan kadar air hasil perendaman pada gabah kering, kadar air berubah secara perlahan dan mencapai tingkat kejenuhan pada rendaman jam ke 48. Data kadar air selama proses perendaman gabah dan beras ditunjukkan pada Gambar 1. 


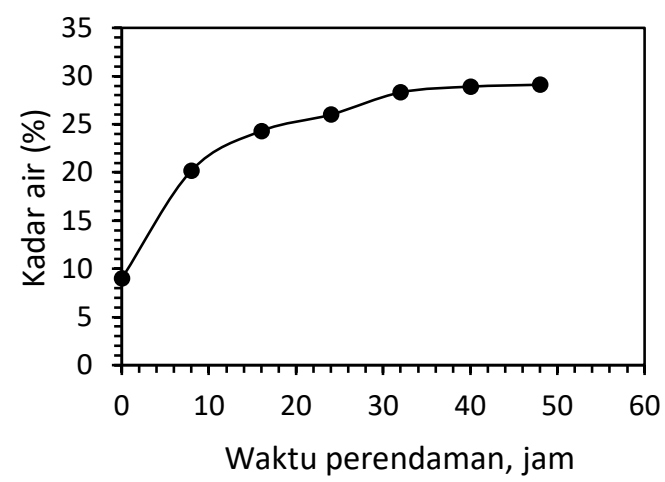

a. Gabah Kering Giling

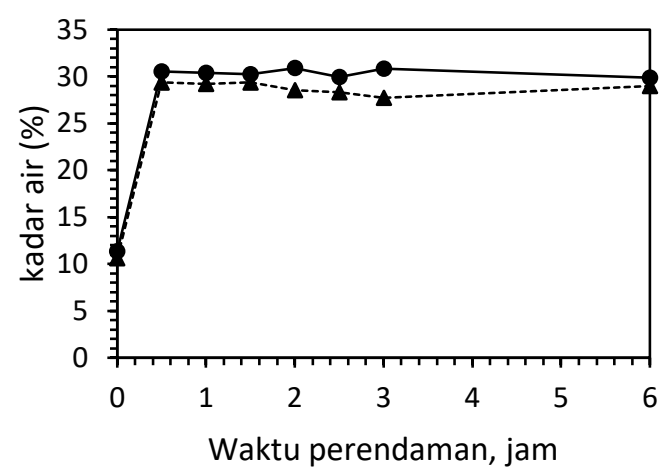

b. Beras Poles

Gambar 1. Pengaruh waktu perendaman terhadap kadar air gabah/beras

Gambar 1 menunjukkan bahwa waktu perendaman 40 jam pada gabah kering giling dapat meningkatkan kadar air dalam gabah menjadi 29\%, sedangkan perendaman beras poles untuk mencapai kadar air kejenuhan memerlukan waktu $0,5 \mathrm{jam}$. Artinya, proses pratanak gabah kering giling akan lebih lama dibandingkan proses pratanak beras poles. Berdasarkan data ini maka dipilih proses pratanak dilakukan pada beras poles.

Respon kadar glukosa darah terhadap konsumsi nasi (beras) diukur setiap 0,5 jam dalam waktu antara $0-2$ jam. Kadar glukosa darah mengalami kenaikan dengan cepat dan mencapai puncak pada waktu 1 jam setelah konsumsi nasi. Berikutnya, kadar glukosa darah mengalami penurunan yang cukup cepat hingga waktu 2 jam setelah konsumsi nasi. Dalam waktu 2 jam ini, kadar glukosa darah sudah mendekati kadar normal dalam darah seorang yang sehat (tidak mengidap diabetes) seperti di awal konsumsi. Pola respon glukosa darah ditunjukkan pada Gambar 2.

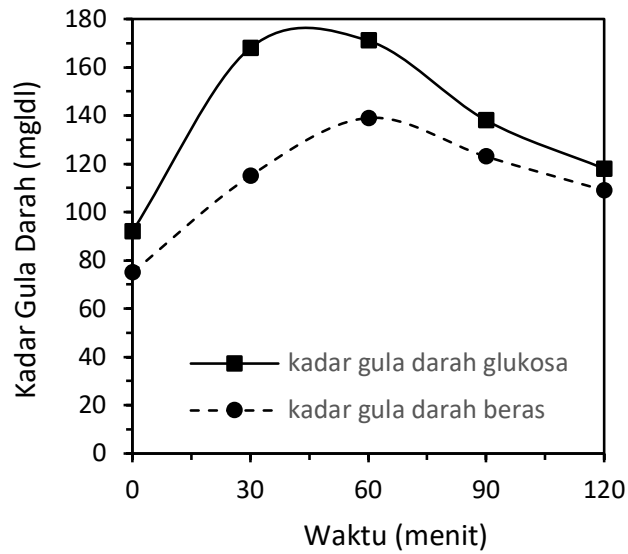

(a)

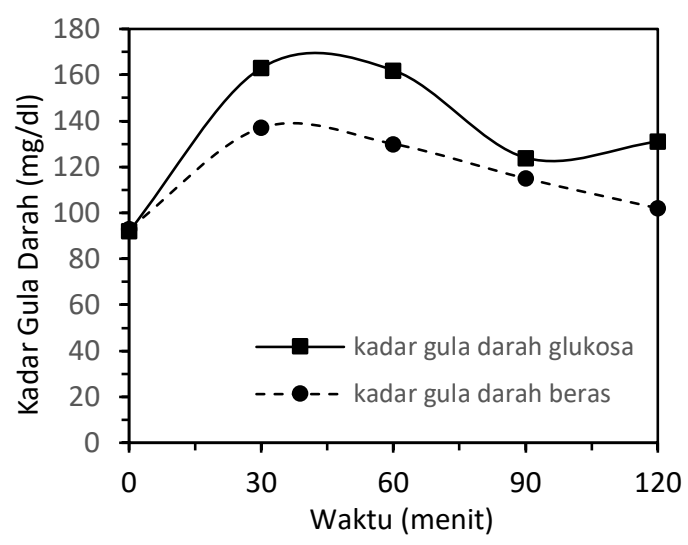

(b)

Gambar 2. Respon glukosa darah hasil konsumsi glukosa dan beras sampel [(a) penguji 1 , (b) penguji 2]

Gambar 2 menunjukkan respon kadar glukosa darah penguji setelah mengkonsumsi glukosa dan sampel nasi dari beras pratanak. Glukosa merupakan standar pembanding untuk menghitung nilai IG, sehingga nilai IG glukosa adalah 100. Data pada Gambar 2 juga menunjukkan bahwa setiap orang memiliki respon kadar glukosa dalam darah yang berbeda sehingga pengukuran nilai IG harus didasarkan pada penguji yang sama antara respon glukosa darah standar dan sampel. Selanjutnya, untuk menghitung nilai IG sampel maka dihitung luasan di bawah kurva bagian respon saja bukan seluruh luasan. Luasan yang digunakan untuk menghitung nilai IG disajikan pada Gambar 3. 


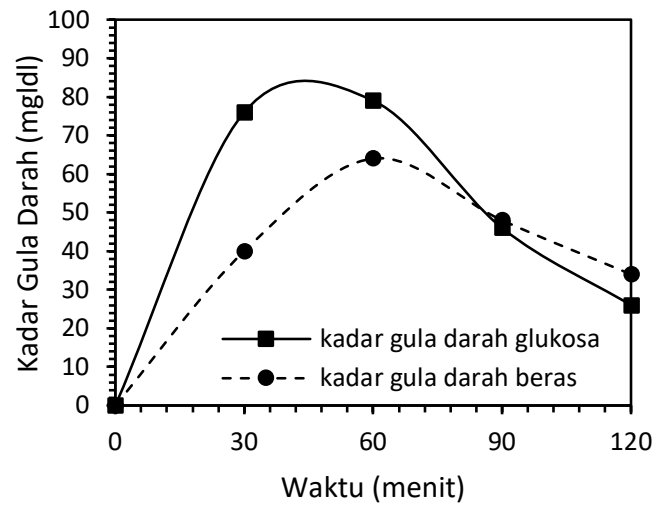

(a)

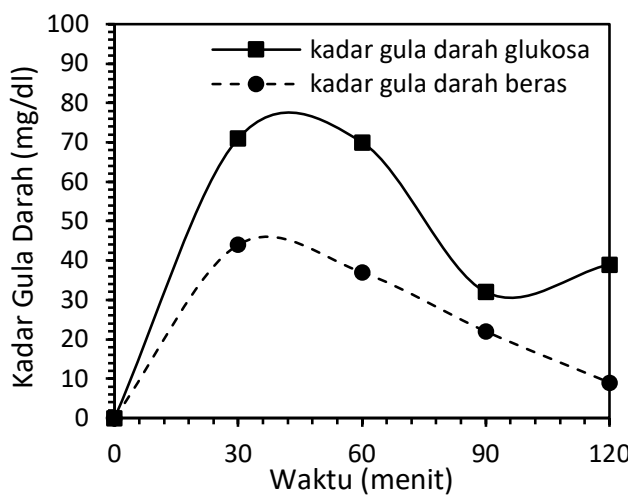

(b)

Gambar 3. Pola respon kadar glukosa dalam darah dalam daerah respon [(a) penguji 1, [b] penguji 2]

Gambar 3 menunjukkan pola respon kadar glukosa darah di bagian daerah respon. Luas daerah di bawah kurva dihitung untuk menentukan nilai IG sampel berdasarkan persamaan (1). Hasil hitungan luasan daerah di bawah kurva dan nilai IG disajikan pada Tabel 2.

Tabel 2. Luas daerah respon dan nilai IG sampel

\begin{tabular}{ccccc}
\hline No. & Penguji & Sampel & Luas & Nilai IG \\
\hline \multirow{2}{*}{1} & \multirow{2}{*}{ Penguji 1} & Glukosa & 6420 & 100 \\
& & Beras+ekstrak & 5070 & 80 \\
2 & Penguji 2 & Glukosa & 5775 & 100 \\
& & Beras + ekstrak & 3225 & 56 \\
\hline
\end{tabular}

Tabel 2 menunjukkan hasil perhitungan nilai IG beras sampel yang dikenakan pratanak menggunakan ekstrak daun keji beling $1 \%$ dan dimasak pada $116^{\circ} \mathrm{C}$ selama 15 menit. Hasilnya belum menunjukkan nilai yang spesifik karena kedua penguji menghasilkan nilai IG yang cukup jauh, namun keduanya menunjukkan bahwa pratanak pada $116^{\circ} \mathrm{C}$ dan ekstrak daun keji beling $1 \%$ tidak berdampak pada penurunan nilai IG bahkan cenderung meningkatkan nilai IG. Hal ini berbeda dengan hasil pratanak yang dilakukan sebelumnya yang berdampak pada penurunan nilai IG dari 54 menjadi 44 [7]. Hasil berbeda ini dimungkinkan karena kondisi pratanak yang berbeda, yaitu pada percobaan ini pratanak beras pada $116{ }^{\circ} \mathrm{C}$ selama 15 menit sedangkan sebelumnya pratanak gabah pada 1,8 atm dan pengeringan bertahap $100{ }^{\circ} \mathrm{C}$ selama 1 jam dan 60 ${ }^{\circ} \mathrm{C}$ selama 25 menit. Diperkirakan bahwa metode pratanak dalam percobaan ini hanya berakibat pada hidrasi pati dan tidak timbul proses kristalisasi karbohidrat sehingga tidak menaikkan kandungan pati resisten. Metode pratanak sebelumnya yang mempertahankan pemanasan yang cukup lama (saat pratanak dan pengeringan) berdampak pada proses kristalisasi senyawa karbohidrat sehingga meningkatkan kadar pati resisten yang juga berdampak pada penurunan nilai IG sampel.

\section{Kesimpulan}

Penyederhanaan proses pratanak dari metode sebelumnya maupun penambahan ekstrak daun keji beling tidak memenuhi hasil sesuai dengan hipotesis, tetapi sebaliknya cenderung meningkatkan nilai IG. Nilai IG hasil pengukuran sampel adalah 56 dan 80. Oleh karena itu perlu perbaikan metode agar dapat menurunkan nilai IG sampel beras sesuai yang dimaksudkan.

\section{Ucapan Terima Kasih}

Ucapan terima kasih disampaikan kepada Rektor Universitas Sebelas Maret yang telah memberikan dana pengabdian pada masyarakat melalui hibah group riset (HGR) UNS dengan no kontrak 453/UN27.21/PN/2020. 


\section{References}

[1] Budijanto, S., Andri, S.I., Faridah, D.N., dan Noviasari, S., 2017, Karakterisasi Kimia dan Efek Hipoglikemik Beras Analog Berbahan Dasar Jagung, Sorghum, dan Sagu Aren, Agritech, 37(4), 402-409. DOI: http:doi.org/22146/agritech.10383.

[2] Hamad, S., Zafar, T.A., dan Sindhu, J., 2018, Parboiled rice metabolism differs in helathy and diabetic individuals with similar improvement in glycemic response, Nutrition, 47, 43-49. https://doi.org/10.1016/j.nut.2017.09.010.

[3] International Diabetes Federation, 2019, IDF diabetes atlas (the 9th ed.) (2019), Retrieved from https://www.diabetesatlas.org/en/Google Scholar.

[4] Kumar, A., Sahoo, S., Sahu, S., Nayak, L., Ngangkham, U., Parameswaran, C., Bose, L.K., Samantaray, S., Kumar, G., dan Sharma, S.G., 2018, Rice with Pulses or cooking oils can be used to elicit lower glicemic response, Journal of Food Composition and Analysis, 71, 1-7. https://doi.org/10.1016/j.jfca.2018.05.003.

[5] Mohanty, S., 2013, Trends in global rice consumption, Rice Today, 12, 44-45.

[6] Septianingrum, E., Liyanan, dan Kusbiyantoro, B., 2016, Review indeks glikemik beras: faktor-faktor yang mempengaruhi dan keterkaitannya dengan kesehatan tubuh, Jurnal Kesehatan, 1(1), 1-9.

[7] Widowati, S., Santosa, B.A.S., Astawan, M., dan Akhyar, 2009, Penurunan indeks glikemik berbagai varietas beras melalui proses pratanak, J. Pascapanen, 6(1), 1-9.

[8] Indrasari, S.D., 2009, Beras untuk Penderita Diabetes, Warta Penelitian dan Pengembangan Pertanian, 32(2), 5-7. 